\title{
HARGA OPSI SAHAM TIPE AMERIKA DENGAN MODEL BINOMIAL
}

\author{
MIA MUCHIA DESDA \\ Program Studi Matematika, \\ Fakultas Matematika dan Ilmu Pengetahuan Alam, Universitas Andalas Padang, \\ Kampus UNAND Limau Manis Padang, Indonesia \\ mia.muchia@yahoo.com
}

\begin{abstract}
Opsi merupakan hak untuk membeli atau menjual saham tertentu pada waktu dan harga yang telah ditentukan. Harga saham diasumsikan memiliki dua nilai periode yang akan datang yaitu naik atau turun begitu pula dengan harga opsi sehingga penentuan harga opsi dapat didekati dengan model binomial. Pada model harga opsi terdapat beberapa faktor yang mempengaruhi yaitu harga pelaksanaan $K$, waktu jatuh tempo $T$, dan harga saham pada saat jatuh tempo $T$. Parameter dasar yang perlu dicari untuk menentukan harga opsi yaitu tingkat kenaikan harga saham $u$, tingkat penurunan harga saham $d$, harga saham awal $S_{0}$, dan probabilitas risiko netral $p$ dan $q$. Setelah keempat parameter tersebut diperoleh maka harga harga opsi tipe Amerika model binomial dapat dimodelkan sebagai berikut

$$
\begin{aligned}
v_{N}\left(S_{N}\right) & =\max \left\{g\left(S_{N}\right), 0\right\} \\
& =\max \left\{g\left(S_{N}\right), \frac{1}{1+r}\left[p V_{n+1}(u s)+q V_{n+1}(d s)\right]\right\}
\end{aligned}
$$

dengan $n=N-1, N-2,, 0$ dan $p=\frac{1+r-d}{(u-d)}, q=\frac{u-1-r}{(u-d)}, r$ adalah tingkat suku bunga bebas risiko, serta $g\left(S_{N}\right)$ adalah nilai intristik saham, $V_{n+1}(u s)$ adalah nilai intristik opsi saat harga saham naik dan $V_{n+1}(d s)$ adalah nilai intristik opsi saat harga saham turun.

Kata Kunci: opsi, opsi jual, opsi beli, tipe Amerika, model binomial, pembeli opsi beli, pembeli opsi jual.
\end{abstract}

\section{Pendahuluan}

Opsi saham merupakan suatu kontrak pemberian hak, bukan kewajiban, dimana adanya jaminan untuk membeli atau menjual suatu asset dari pihak pemegang opsi saham kepada pembeli opsi saham dalam menjalankan haknya [7]. Hak pembeli opsi saham dapat berupa hak untuk membeli suatu aset yang sering disebut dengan opsi beli dan hak untuk menjual aset kepada pemegang opsi saham dengan harga yang disepakati disebut dengan opsi jual. Opsi saham juga dapat dikelompokkan berdasarkan aturan waktu pelaksanaannya (expiration date). Pengelompokkan tipe opsi saham ini yang sangat terkenal adalah opsi saham tipe Amerika dan opsi saham tipe Eropa. Opsi saham yang dilaksanakan kapan saja sampai tanggal jatuh temponya disebut dengan opsi saham tipe Amerika. Sedangkan opsi saham yang hanya dapat dilaksanakan pada saat tanggal jatuh temponya disebut dengan opsi saham tipe Eropa. Dalam penelitian ini, opsi saham yang digunakan berdasarkan opsi saham tipe Amerika. 
Harga opsi adalah keuntungan yang diperoleh pembeli opsi. Harga opsi tipe Amerika lebih sulit diestimasi dibandingkan dengan harga opsi tipe Eropa, karena harga opsi tipe Amerika tidak hanya bergantung pada harga saham saat jatuh tempo, tetapi juga pada fluktuasi harga saham selama opsi itu berjalan. Pada Tulisan ini akan dikaji harga opsi saham tipe Amerika dengan model binomial serta penerapannya pada harga saham perusahaan Rio Tinto Plc (RIO).

\section{Model Harga Opsi Beli dan Opsi Jual Saham}

Jika harga saham saat opsi dilaksanakan $S_{T}$ lebih besar dari harga pelaksanaan $K$ maka besarnya keuntungan yang diperoleh pemegang opsi beli adalah $S_{T}-K$. Sedangkan jika $S_{T} \leq K$ maka keuntungan yang diperoleh pemegang opsi beli adalah nol. Jadi keuntungan yang akan diperoleh pemegang opsi beli dapat bernilai nol atau selisih dari harga saham saat opsi dilaksanakan dengan harga pelaksanaan.

Secara matematis harga opsi beli saat opsi dilaksanakan $C_{T}$ dapat dimodelkan sebagai berikut

$$
C_{T}= \begin{cases}S_{T}-K, & \text { jika } S_{T}>K \\ 0, & \text { jika } S_{T} \leq K\end{cases}
$$

sehingga

$$
C_{T}=\operatorname{maks}\left(0, S_{T}-K\right),
$$

artinya harga opsi merupakan nilai maksimal antara 0 dan selisih harga saham dengan harga pelaksanaan saat opsi beli dilaksanakan.

Jika harga saham saat opsi dilaksanakan $S_{T}$ lebih kecil dari harga pelaksanaan $K$ maka besarnya keuntungan yang diperoleh pemegang opsi jual adalah $K-S_{T}$. Sedangkan jika $S_{T} \geq K$ maka keuntungan yang diperoleh pemegang opsi jual adalah nol. Jadi keuntungan yang akan diperoleh pemegang opsi jual dapat bernilai nol atau selisih dari harga pelaksanaan dengan harga saham saat opsi.

Secara matematis harga opsi jual saat opsi dilaksanakan $P_{T}$ dapat dimodelkan sebagai berikut

$$
P_{T}= \begin{cases}K-S_{T}, & \text { jika } S_{T}<K \\ 0, & \text { jika } S_{T} \geq K\end{cases}
$$

sehingga

$$
P_{T}=\operatorname{maks}\left(0, K-S_{T}\right),
$$

artinya harga opsi merupakan nilai maksimal antara 0 dan selisih harga saham dengan harga pelaksanaan dengan harga saham saat opsi dilaksanakan.

\section{Perubahan Harga Saham dengan Model Binomial}

Harga saham merupakan nilai diskret yang akan mengalami perubahan harga saham pada periode mendatang yaitu harga saham akan naik atau harga saham turun yang sesuai dengan asumsi distribusi binomial. Harga saham dapat mengalami kenaikan dengan tingkat kenaikan $u$ dengan syarat $u>1$ atau dapat turun dengan tingkat penurunan $d$ dengan syarat $0<d<1$. 


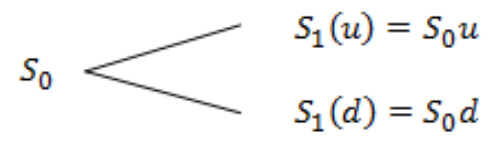

Fig. 1. Pohon Binomial Harga Saham Untuk Satu Periode

Jika $S_{0}$ merupakan harga saham awal maka pada satu periode mendatang $S_{0}$ akan memiliki dua kemungkinan nilai yaitu $S_{1}(u)$ atau $S_{1}(d)$ pada saat $t=1$, perubahan harga saham dapat diilustrasikan sebagai berikut

Jika diasumsikan selama interval waktu sampai jatuh tempo, harga saham akan meningkat dengan kenaikan $u$ dan peluang $p$, atau harga saham akan turun dengan tingkat penurunan $d$ dan peluang $1-p$, maka harga saham pada waktu $S_{t+1}$ akan berubah menjadi $u S_{t}$ atau $d S_{t}$ pada periode mendatang.

Selama waktu sampai jatuh tempo $(T), T$ dapat dibagi menjadi $n$ periode sehingga menghasilkan lama waktu $\frac{T}{n}$ [1]. Pada akhir periode harga saham bisa naik atau turun. Sehingga pada akhir periode pertama harga saham akan menjadi

$$
S_{t+1}=\left\{\begin{array}{l}
S_{t} u, \text { dengan peluang } p \\
S_{t} d, \text { dengan peluang } 1-p
\end{array}\right.
$$

Selanjutnya setelah interval ke-2, harga saham pada akhir periode kedua menjadi

$$
S_{t+2}=\left\{\begin{array}{l}
S_{t} u^{2}, \text { dengan peluang } p^{2} \\
S_{t} u d, \text { dengan peluang } 2 p(1-p) \\
S_{t} d^{2}, \text { dengan peluang }(1-p)^{2}
\end{array}\right.
$$

Pada akhir periode kedua ada tiga hasil yang mungkin terjadi, yaitu harga saham meningkat pada dua interval, harga saham meningkat kemudian menurun atau sebaliknya dan harga saham turun pada dua interval.

Misalkan $J$ menyatakan frekuensi kenaikan harga saham yang muncul pada $n$ periode perubahan harga saham. Dengan kata lain, $J$ merupakan peubah acak diskret. Maka proses selanjutnya, pada akhir periode keempat terdapat lima hasil yang mungkin terjadi dan seterusnya. Jadi setelah waktu ke- $n$, akan terdapat $n+1$ perubahan harga saham, sehingga harga saham pada akhir periode $t+n$ adalah

$$
S_{t+n}=S_{0} u^{j} d^{n-j} ; j=0,1,2, \ldots, n
$$

dengan fkp $f(j)$ sebagai berikut

$$
f(j)=C_{j}^{n} p^{j}(1-p)^{n-j} ; j=0,1,2, \ldots, n
$$

Harga saham saat mencapai jatuh tempo $T$ sama nilainya ketika harga saham $S_{t}$ berubah pada akhir periode ke- $n$ sehingga $S_{T}=S_{t+n}$.

Dari persamaan (1), maka harga saham pada waktu jatuh tempo $T$ dapat dituliskan sebagai berikut

$$
S_{T}=S_{0} u^{j} d^{n-j} \text { dengan peluang } C_{j}^{n} p^{j}(1-p)^{n-j} ; j=0,1,2, \ldots, n
$$


dengan mengasumsikan $u=\frac{1}{d}$, diperoleh

$$
(\ln d)^{2}=\frac{\mu^{2} T^{2}}{(1-2 p)^{2} n^{2}}
$$

Selanjutnya akan diperoleh

$$
p=\frac{1}{2}+\frac{1}{2} \frac{\mu}{\sigma} \sqrt{\frac{T}{n}}
$$

Dalam hal ini, untuk $n$ yang semakin besar atau $n$ mendekati tak hingga nilai empiris untuk $\mu n$ dan $\sigma^{2} n$ yaitu $\mu n \rightarrow \mu T$ dan $\sigma^{2} n \rightarrow \sigma^{2} T$ untuk $n \rightarrow \infty$. [3] Sehingga persamaan (3) menjadi

$$
\begin{aligned}
(\ln d)^{2} & =\frac{\mu^{2} T^{2}}{(1-2 p)^{2} n^{2}} \\
(\ln d) & =\frac{\mu T}{(1-2 p) n}
\end{aligned}
$$

Kemudian dengan mensubstitusikan persamaan (4) pada persamaan di atas diperoleh

$$
\begin{gathered}
\ln d=\frac{\mu n}{\left(1-2\left(\frac{1}{2}+\frac{1}{2} \frac{\mu}{\sigma} \sqrt{\frac{T}{n}}\right)\right) n}=-\sigma \sqrt{\frac{T}{n}} \\
d=e^{-\sigma \sqrt{\frac{T}{n}}},
\end{gathered}
$$

karena $d=\frac{1}{u}$ maka $u=e^{\sigma \sqrt{\frac{T}{n}}}$.

Nilai probabilitas risiko netral $p$ dan $q=1-p$ dapat dicari dengan menggunakan persamaan $E\left[S_{T}\right]=p u+(1-p) d=(1+r)$. Dari persamaan tersebut diperoleh

$$
p=\frac{1+r-d}{(u-d)} \text { dan } q=\frac{u-1-r}{(u-d)}
$$

Dalam menentukan model untuk menentukan harga opsi maka dapat digunakan prinsip dasar bahwa pengembalian portofolio cegah risiko sama dengan suku bunga bebas risiko, sehingga hasil portofolio periode mendatang harus sama dengan biaya portofolio cegah risiko yang diterima periode mendatang. Hasil portofolio cegah risiko akan sama baik ketika harga saham meningkat atau menurun, maka dapat digunakan salah satu keadaan hasil portofolio cegah risiko. Sehingga dapat diperoleh persamaan

$$
(1+r)\left(\Delta S_{0}-V_{0}\right)=u \Delta S_{0}-V_{1}(u)
$$

Dengan menyederhanakan dan mensubstitusikan nilai rasio cegah risiko $\Delta=$ $\frac{V_{1}(u)-V_{1}(d)}{(u-d) S_{0}}=\frac{V_{1}(u)-V_{1}(d)}{S_{1}(u)-S_{1}(d)}$ maka diperoleh

$$
(1+r) V_{0}=V_{1}(u) \frac{1+r-d}{(u-d)}+V_{1}(d) \frac{u-1-r}{(u-d)}
$$

sehingga untuk memperoleh harga opsi saham satu periode adalah

$$
V_{0}=\frac{1}{(1+r)}\left[p V_{1}(u)+q V_{1}(d)\right]
$$


Untuk mendapatkan harga opsi dua periode terlebih dahulu perlu ditentukan nilai intristik opsi saat harga saham naik $V_{1}(u)$ dan nilai intristik opsi saat harga saham turun $V_{1}(d)$ yaitu:

$$
\begin{aligned}
& V_{1}(u)=\frac{1}{(1+r)}\left[p V_{2}(u u)+q V_{2}(u d)\right] \\
& V_{1}(d)=\frac{1}{(1+r)}\left[p V_{2}(d u)+q V_{2}(d d)\right]
\end{aligned}
$$

Dengan mensubstitusikan nilai intristik opsi dari kedua keadaan sehingga diperoleh model untuk menentukan harga opsi dua periode sebagai berikut:

$$
\begin{aligned}
V_{0} & =\frac{1}{(1+r)}\left[p V_{1}(u)+q V_{1}(d)\right] \\
& =\frac{1}{(1+r)}\left[p \frac{1}{(1+r)}\left[p V_{2}(u u)+q V_{2}(u d)\right]+q \frac{1}{(1+r)}\left[p V_{2}(d u)+q V_{2}(d d)\right]\right. \\
& =\frac{1}{(1+r)^{2}}\left[p^{2} V_{2}(u u)+2 p q V_{2}(u d)+q^{2} V_{2}(d d)\right]
\end{aligned}
$$

Jadi, persamaan untuk memperoleh harga opsi dua periode adalah

$$
V_{0}=\frac{1}{(1+r)^{2}}\left[p^{2} V_{2}(u u)+2 p q V_{2}(u d)+q^{2} V_{2}(d d)\right]
$$

Untuk model penentuan harga opsi model binomial $n$ periode maka akan terdapat $n+1$ keadaan harga opsi dan harga saham pada akhir periode opsi. Untuk memperoleh model harga opsi $n$ periode dapat ditentukan dengan melihat pola yang terbentuk dari persamaan opsi satu periode, dua periode dan seterusnya. Rumus untuk mencari nilai intristik opsi $n$ periode sebagai berikut

$$
V_{n}\left(\omega_{1} \omega_{2} \ldots \omega_{n}\right)=\frac{1}{(1+r)}\left[p V_{n+1}\left(\omega_{1} \omega_{2} \ldots \omega_{n} u\right)+q V_{n+1}\left(\omega_{1} \omega_{2} \ldots \omega_{n} d\right)\right]
$$

Nilai $V_{n}$ tergantung pada kondisi perubahan harga saham satu periode mendatang apakah harga saham mengalami kenaikan atau penurunan. $\omega_{i}$ adalah kombinasi $n$ kali dari $u$ dan $d$ untuk $i=1,2,, n . \omega=u$ menunjukkan bahwa harga saham mengalami kenaikan dan $\omega=d$ menunjukkan harga saham mengalami penurunan. Sedangkan rumus untuk memperoleh harga opsi untuk $n$ periode adalah

$$
V_{0}=\left(\frac{1}{1+r}\right)^{n} \sum_{j=0}^{n} p^{n-j} q^{j}\left[\operatorname{maks}\left(S_{0} u^{j} d^{n-j}-K, 0\right)\right]
$$

Persamaan (5) merupakan model untuk menghitung nilai opsi beli sedangkan persamaan untuk mendapatkan harga opsi jual adalah

$$
V_{0}=\left(\frac{1}{1+r}\right)^{n} \sum_{j=0}^{n} p^{n-j} q^{j}\left[\operatorname{maks}\left(K-S_{0} u^{j} d^{n-j}, 0\right)\right]
$$

Untuk selanjutnya harga opsi beli dilambangkan dengan $C$ dan harga opsi jual dengan $P$. 


\section{Harga Opsi Tipe Amerika dan Penerapannya}

Opsi tipe Amerika merupakan opsi yang dapat dilaksanakan sebelum atau pada saat jatuh tempo. Berdasarkan persamaan untuk memperoleh nilai intristik opsi maka dapat ditentukan Algoritma Amerika untuk menentukan harga opsi. Misalkan $g$ adalah fungsi yang menunjukkan nilai intristik dari suatu opsi yang tergantung dari harga saham pada saat $N$ sehingga fungsi tersebut dapat dinotasikan dengan $g\left(S_{N}\right)$ dan harga opsi $V_{n}$ sebagai fungsi $v_{n}$ dari harga saham pada waktu ke- $n$. Fungsi $V_{n}$ dapat ditulis sebagai $V_{n}=v_{n}\left(S_{n}\right)$ dengan $n=0,1,2,, N$. Algoritma Amerika yang dapat digunakan untuk menentukan harga opsi adalah sebagai berikut:

$$
\begin{aligned}
& v_{N}\left(S_{N}\right)=\operatorname{maks}\left\{g\left(S_{N}\right), 0\right\} \\
& v_{N}\left(S_{N}\right)=\operatorname{maks}\left\{g\left(S_{N}\right), \frac{1}{1+r}\left[p V_{n+1}(u s)+q V_{n+1}(d s)\right]\right\}
\end{aligned}
$$

dengan $n=N-1, N-2,0$ dan $p=\frac{1+r-d}{(u-d)}, q=\frac{u-1-r}{(u-d)}$. Jadi, $V_{n}=v_{n}\left(S_{n}\right)$ merupakan harga opsi untuk opsi tipe Amerika.

Dalam menerapkan model binomial diperlukan sebuah data yang dapat dianalisis untuk mengetahui harga dari opsi saham tersebut. Data saham yang digunakan dalam pembahasan ini adalah data penutupan harga saham perusahaan Rio Tinto Plc (RIO). Rio Tinto plc (RIO) adalah perusahaan yang bergerak dibidang pertambangan dan pengolahan sumber daya mineral.

Data saham yang dikumpulkan adalah data frekuensi harian (kecuali hari libur dan non trading days) pada periode 18 Januari 2011 sampai 20 Januari 2012 dengan total pengamatan sebanyak 255 data.

\begin{tabular}{|l|l|l|}
\hline \multicolumn{1}{|c|}{ Variabel } & \multirow{2}{*}{ 1 Periode } & \multirow{2}{*}{ 2 Periode } \\
\cline { 1 - 2 } & & \\
\hline Harga Saham Awal $\left(S_{0}\right)$ & 57.34 & 57.34 \\
\hline Harga Pelaksanaan $(K)$ & 47.50 & 47.50 \\
\hline Tingkat suku bunga $(r)$ & 0.0025 & 0.0025 \\
\hline Waktu Jatuh Tempo $(T)$ & 0.249 & 0.125 \\
\hline Volatilitas $(\sigma)$ & 0.4836 & 0.4836 \\
\hline \multicolumn{2}{|c|}{ OUTPUT } & \multicolumn{2}{|}{} \\
\hline $\boldsymbol{u}$ & 1.015237 & 1.010751 \\
\hline $\boldsymbol{d}$ & 0.984991 & 0.989364 \\
\hline $\boldsymbol{p}$ & 0.578875 & 0.614221 \\
\hline $\boldsymbol{q}$ & 0.421125 & 0.385779 \\
\hline
\end{tabular}

Fig. 2. Tabel Input dan Output Nilai Parameter

Model harga opsi saham tipe Amerika dengan model binomial diterapkan pada saham perusahaan Rio Tinto Plc (RIO) yang digunakan dalam mengambil keputusan untuk melakukan investasi pada opsi, sehingga para investor dapat memilih waktu yang tepat untuk melaksanakan opsi. Berdasarkan perhitungan opsi untuk satu periode dan dua periode pemegang opsi beli disarankan untuk melaksanakan opsinya pasa saat $t=2$ yaitu pada tanggal 20 April 2012. Karena harga saham perusahaan Rio Tinto Plc (RIO) mengalami kecenderungan naik maka opsi beli lebih menguntungkan dibandingkan opsi jual, sehingga bagi pemegang opsi jual disarankan untuk menjual opsi yang dimiliki. Berdasarkan hasil perhitungan akan diperoleh hasil laba (rugi) sebagai berikut: 
1. Pemegang opsi beli akan memperoleh keuntungan jika harga saham saat opsi dilaksanakan lebih besar dari harga pelaksanaan atau $S_{T}>K$. Setelah dibandingkan dengan besarnya harga opsi beli maka pembeli opsi beli memperoleh keuntungan maksimal \$32.4234, sedangkan kerugian yang diperoleh penjual opsi beli sebesar keuntungan pembeli opsi. Jadi semakin tinggi harga saham saat opsi dilaksanakan keuntungan yang diperoleh pembeli opsi beli semakin besar.

2. Pembeli opsi jual akan memperoleh keuntungan jika harga pelaksanaan lebih besar dari harga saat opsi dilaksanakan atau $K>S_{T}$. Setelah dibandingkan dengan nilai pada opsi jual maka laba maksimal yang diperoleh pembeli opsi jual adalah sebesar $\$ 22.50$ sebaliknya penjual opsi jual mengalami kerugian sebesar \$22.50. Jadi semakin kecil harga saham saat opsi dilaksanakan dibandingkan harga pelaksanaan maka keuntungan yang diperoleh pembeli semakin besar.

\section{Ucapan Terima kasih}

Penulis mengucapkan terima kasih kepada Bapak Dodi Devianto, Ibu Izzati Rahmi, Ibu Maiyastri dan Bapak Admi Nazra yang telah memberikan masukan dan saran sehingga makalah ini dapat diselesaikan dengan baik.

\section{Daftar Pustaka}

1. Adams, A. 2003. Investment Mathematics. Canada: John Wiley dan Sons Ltd.

2. Bain dan M. Engelhardt . 1992. Introduction to Probability and Mathematical Stocastic. Second edition. California: Duxbury Press.

3. Capinski, M. dan T. Zastawniak. 2004. Mathematics for Finance: an introduction to financial engineering. Springer undergraduate mathematics series. United States of America: Springer-Verlag.

4. Halim, A. 2005. Analisis Investasi. Edisi Kedua. Jakarta: Salemba Empat.

5. Husnan, S. 1998. Dasar-Dasar Teori Portfolio dan Analisis Sekuritas. Edisi ketiga. Yogyakarta: AMP.

6. Tandelilin, E. 2001. Analisis Investasi dan Manajemen PortfolioAnalisis Investasi dan Manajemen Portfolio. Edisi Pertama. Yogyakarta: BPFE-Yogyakarta. 